\title{
Natural Killer Cell in Systemic Lupus Erythematosus
}

\author{
DEFECTS IN EFFECTOR LYTIC ACTIVITY AND \\ RESPONSE TO INTERFERON AND INTERFERON INDUCERS
}

\author{
W. L. Sibbitt, Jr., P. M. Mathews, and A. D. Bankhurst, Department of \\ Medicine, School of Medicine, University of New Mexico, \\ Albuquerque, New Mexico 87131
}

\begin{abstract}
A B S T R A C T Spontaneous cytotoxicity mediated by natural killer (NK) cells is impaired in several human diseases including systemic lupus erythematosus (SLE). The precise mechanism(s) by which NK activity is suppressed in patients with SLE is generally unknown. The present study was designed to focus on cellular defects per se in NK cells from patients with SLE. It was observed that the usual enhancing effect of interferon (IF) and IF inducers was markedly impaired in SLE patients. Of 24 SLE patients studied, 17 had significantly decreased NK activity relative to controls. NK activity had a significant negative correlation with clinical activity score $(r=-0.56, P<0.005)$ but was not correlated with corticosteroid dose, antinuclear antibody titers, total hemolytic complement (CH50), or sedimentation rate. Furthermore, significant depressions in NK activity correlated with variations in disease activity in six patients followed serially. Depressed NK function could not be reversed by prolonged in vitro incubation at $37^{\circ} \mathrm{C}$ or with protease treatment. Furthermore, depressed NK activity was not altered by removal of glass adherent cells nor was a suppression of NK activity in normal controls seen by the addition of SLE peripheral mononuclear cells. No reversal of depressed activity to normal levels was seen by the addition of indomethacin nor did the supernatants from SLE cell cultures cause a suppression of normal NK function. NK activity in SLE patients did not respond normally to IF inducers (poly-I:C and concanavalin A) even if the SLE patients had normal NK function. The response of SLE cells to exogenous IF was also impaired. The number of effector-target conjugates was quantitated with several target cells (K562, Yac-1, Fravel) in SLE patients and controls. A
\end{abstract}

Received for publication 3 June 1982 and in revised form 19 January 1983. significant correlation between the proportion of glass nonadherent mononuclear cells that formed effectortarget conjugates with these various targets and the magnitude of NK lysis was observed. However, SLE and normal subjects had equal numbers of effectortarget conjugates independent of NK function. Release of a soluble cytotoxic factor was induced with concanavalin A, and was markedly impaired in SLE patients relative to normal controls. Thus, impaired NK cell function in SLE does not appear to be related to cell-mediated suppressive mechanisms or to the deletion of effector cells; rather, the decreased NK activity may be related to an impaired release of a soluble cytotoxic factor.

\section{INTRODUCTION}

Natural cytotoxicity is thought to be a distinct arm of the host immune surveillance system (1) and may be important in the elimination of tumors (2) and virusinfected cells ( 3 ). The natural killer $(\mathrm{NK})^{1}$ cell is morphologically a large granular lymphocyte (4) and can be partially purified with a number of techniques (5). It spontaneously binds to susceptible targets and effects rapid lysis (6). This progression of binding and subsequent lysis can be directly visualized and followed sequentially (7). NK cell-mediated cytotoxicity is abnormal in a number of human disease states including systemic lupus erythematosus (SLE) (8), Sjögren's syndrome (9), Chediak-Higashi syndrome (10), malignant melanoma (11), and advanced epitheliod carcinomas (12). In SLE the abnormalities in NK func-

\footnotetext{
${ }^{1}$ Abbreviations used in this paper: ALA, antilymphocyte antibodies; CH50, total hemolytic complement; Con A, concanavalin $\mathrm{A} ; \mathrm{E} / \mathrm{T}$ ratio, effector/target ratio; IF, interferon; NK cells, natural killer cells; NKCF, NK cell cytotoxic factor; SLE, systemic lupus erythematosus.
} 
tion can be profound $(13,14)$, and in that respect present an ideal system for the study of derangements in this host defense mechanism.

Various studies have implicated antilymphocyte antibodies (ALA) (14) and immune complexes (13) in the pathogenesis of the defect in NK activity found in SLE. Primary abnormalities in lymphocyte function have been described in $\operatorname{SLE}(15,16)$, but cellular defects per se in NK effector cells have not been thoroughly evaluated. In spite of the presence of ALA reactive with NK effector cells (14), an actual in vivo deletion of the mononuclear cell subpopulation responsible for NK activity has not been demonstrated. In addition, many SLE patients with decreased NK activity do not have detectable serum ALA (13).

This study was designed to investigate NK activity in SLE and to focus on specific defects in the mononuclear cells that mediate NK activity. It was observed that the usual enhancing effect of interferon (IF) and IF inducers was markedly impaired in SLE patients. In addition, the release of natural killer cell cytotoxic factor (NKCF) that mediates NK cell lytic activity (17), was also abnormal.

\section{METHODS}

Subjects. All patients included in this study were followed in the University of New Mexico Rheumatology Clinics and fulfilled the strict criteria for SLE as defined by the American Rheumatologic Association (18). The patients were followed serially through exacerbations and remissions over the course of $2 \mathrm{yr}$. Clinical data are included in Table I. All SLE patients and controls were female. Clinical disease activity was scored according to the method of Barada et al. (19): $0=$ no activity; 1 = mild clinical disease (fatigue, arthralgias, mild skin rash); 2 = moderately severe disease, but without manifestations of renal or central nervous system involvement with the disease flare (polyarthritis, serositis,

TABLE I

Patient Profile

\begin{tabular}{|c|c|c|c|c|c|c|}
\hline Age & $\begin{array}{c}\text { Clinical• }^{\bullet} \\
\text { activity score }\end{array}$ & CH5Ot & ANA & $\begin{array}{c}\text { Sedimentation§ } \\
\text { rate }\end{array}$ & $\begin{array}{c}\text { Prednisone } \\
\text { dosage }\end{array}$ & $\begin{array}{c}\mathbf{N K}^{\prime \prime} \\
\text { activity }\end{array}$ \\
\hline & & & & & $m g$ qd & \\
\hline 34 & 0 & 116 & Diffuse 1:10 & 16 & None & 42.0 \\
\hline 40 & 0 & 82 & Diffuse 1:100 & 14 & None & 16.2 \\
\hline 65 & 1 & 75 & Diffuse 1:200 & 30 & 10 & 89.0 \\
\hline 44 & 1 & 116 & Negative & ND & None & 44.3 \\
\hline 52 & 1 & 100 & Negative & 30 & 10 & 35.0 \\
\hline 42 & 1 & 125 & Diffuse 1:50 & 40 & 10 & 50.5 \\
\hline 37 & 1 & 100 & Negative & 24 & None & 42.6 \\
\hline 42 & 1 & ND & Negative & 56 & 5 & 44.6 \\
\hline 38 & 1 & 52 & Diff use 1:200 & 14 & None & 30.5 \\
\hline 54 & 1 & 70 & Speckled & 31 & 10 & 47.9 \\
\hline 62 & 1 & ND & Speckled & 31 & 10 & 52.5 \\
\hline 19 & 2 & 57 & Speckled 1:10 & 19 & 10 & 18.4 \\
\hline 30 & 2 & 83 & Negative & 48 & 10 & 18.2 \\
\hline 28 & 2 & 20 & Speckled 1:400 & 32 & 40 & 36.0 \\
\hline 32 & 2 & 62 & Diffuse 1:400 & 32 & 10 & 17.7 \\
\hline 32 & 2 & 95 & Negative & 26 & 10 & 20.9 \\
\hline 42 & 2 & 75 & Diffuse 1:10 & 30 & 20 & 15.8 \\
\hline 30 & 2 & 105 & Diffuse 1:40 & 20 & None & 30.0 \\
\hline 26 & 2 & 41 & Speckled 1:10 & 20 & 10 & 12.6 \\
\hline 29 & 2 & ND & Diffuse 1:10 & 25 & 10 & 22.5 \\
\hline 26 & 3 & 62 & Speckled & 16 & 60 & 15.8 \\
\hline 38 & 3 & 20 & Speckled 1:40 & 58 & 80 & 5.0 \\
\hline 58 & 3 & 60 & Negative & 48 & 80 & 20.9 \\
\hline 34 & 3 & 45 & Diffuse & 26 & 60 & 0.0 \\
\hline
\end{tabular}

- Clinical activity was defined on a score of $0-3$ as described in the Methods.

† $\mathrm{CH} 50$, normal range $50-200$.

\$ Westergren method, normal $<20$.

"Expressed as percent ${ }^{51} \mathrm{Cr}$ release at a 50:1 E/T ratio.

ANA, antinuclear antibodies; ND, not determined. 
rash); 3 = significant multisystem disease with renal and/or central nervous system involvement.

Peripheral blood mononuclear cells (PBMC). PBMC were isolated from heparinized whole blood by centrifugation on Hypaque-Ficoll gradients (20). Cells from the interface were washed three times with phosphate-buffered saline, and resuspended in medium RPMI 1640 (Gibco Laboratories, Grand Island Biological Co., Grand Island, NY) with penicillin $(100 \mathrm{IU} / \mathrm{ml})$, streptomycin $(100 \mu \mathrm{g} / \mathrm{ml})$, and $10 \%$ heat-inactivated human $\mathrm{AB}$ serum. Cell viability was $>99 \%$ as determined by trypan blue exclusion and contained from 2 to $20 \%$ monocytes by benzidine peroxidase staining (21). PBMC at $5 \times 10^{6}$ cells $/ \mathrm{ml}$ were resuspended in RPMI 1640 medium containing $10 \%$ human $\mathrm{AB}$ serum, placed in glass wool columns $(0.5 \mathrm{~g}$ glass wool in a $10-\mathrm{ml}$ plastic syringe barrel), and incubated for $30 \mathrm{~min}$ at $37^{\circ} \mathrm{C}$. The glass wool nonadherent cells were eluted with $15-\mathrm{ml}$ of warm medium Final suspension contained 0-1\% monocytes as determined by peroxidase staining.

Protease treatment of PBMC. Mononuclear cells were treated with protease (type XI, Sigma Chemical Co., St Louis, MO) as described by Lobo et al. (22). After incubation with protease for $25 \mathrm{~min}$ at $37^{\circ} \mathrm{C}\left(1.2 \mathrm{mg}\right.$ protease $/ 10^{7}$ cells $)$ the cells were washed three times in media, resuspended at $5 \times 10^{6}$ cells $/ \mathrm{ml}$, and cultured overnight in media at $37^{\circ} \mathrm{C}$ Cell viability as determined by trypan blue exclusion was $>95 \%$.

Poly-I:C and concanavalin A (Con A). Poly-I:C (p4136, Sigma Chemical Co.) at $100 \mu \mathrm{g} / \mathrm{ml}$ and Con A (C-2010, Sigma Chemical Co.) at $50 \mu \mathrm{g} / \mathrm{ml}$ were incubated with PBMC for $16 \mathrm{~h}$ at $37^{\circ} \mathrm{C}$ before being placed in cytotoxic assays. Cell viability was $>96 \%$.

Indomethacin. Indomethacin (Sigma Chemical Co.) was dissolved in $95 \%$ ethanol at $10 \mathrm{mg} / \mathrm{ml}$. The solution was then diluted with RPMI 1640 as necessary to achieve the appropriate final concentrations. The small amount of ethanol in the cultures did not affect cell viability or NK function. Indomethacin at $1 \mu \mathrm{g} / \mathrm{ml}$ was incubated with PBMC for 16 $h$ at $37^{\circ} \mathrm{C}$. The cells were washed with media before use in subsequent assays.

IF. PBMC were incubated with alpha IF (National Institutes of Health standard, G023-90X-577, Bethesda, MD) at $100 \mathrm{U} / \mathrm{ml}$ at $37^{\circ} \mathrm{C}$ for $30 \mathrm{~min}$. Better augmentation of cytolytic activity was obtained if IF was present throughout the assay.

Supernatants. Normal control and SLE cells in RPMI $1640 / 10 \% \mathrm{AB}$ serum were cultured at $1.25 \times 10^{6}$ cells $/ \mathrm{ml}$ for $16 \mathrm{~h}$. The supernatant was collected and then incubated with fresh effector cells at $1.25 \times 10^{6}$ cells $/ \mathrm{ml}$ of supernatant for $2 \mathrm{~h}$ before placement in the NK assay.

Sequential addition of SLE cells to normal control cells. SLE cells were added to normal control PBMC $\left(2.5 \times 10^{5}\right.$ cells/well) in microtiter plates at the following SLE control ratios: $0: 1,0.2: 1,0.4: 1,0.6: 1$, and $1: 1$. These preparations were then cultured for $16 \mathrm{~h}$ before placement in the NK assay.

NKCF release assay. NKCF was induced in a manner similar to that described by Wright and Bonavida $(17,23)$. Briefly, PBMC at $20 \times 10^{6} \mathrm{cells} / \mathrm{ml}$ in medium were incubated with Con A at $5 \mathrm{mg} / \mathrm{ml}$ at $37^{\circ} \mathrm{C}$ for $36 \mathrm{~h}$, subsequently the supernatant was harvested after centrifugation at 400 $g$ for $5 \mathrm{~min}$. Supernatants were stored at $-70^{\circ} \mathrm{C}$ until use, at which time they were passed through a $0.45-\mu \mathrm{m}$ filter. The NKCF activity of each supernatant was determined by pipetting $1 \mathrm{ml}$ of $\mathrm{K} 562$ targets suspended in fresh medium at a concentration of $2 \times 10^{5}$ cells $/ \mathrm{ml}$ and $0.1 \mathrm{ml}$ of the NKCF supernatant into each of three wells of a sterile flat bottom microtiter plate. Control wells received, instead of supernatant, $0.1 \mathrm{ml}$ of either medium or medium with Con A. For both controls, K562 viability at the end of the assay was $>95 \%$. Plates were incubated at $37^{\circ} \mathrm{C}$ in $5 \% \mathrm{CO}_{2}$ for 48 $\mathrm{h}$ at which time K562 viability was determined by trypan blue exclusion. A minimum of 200 cells were counted per well, and the percentage of killed cells was determined. This percentage reflected the relative cytotoxic activity of each supernatant. Specificity of NKCF induced in this manner was essentially identical to that described previously (23).

NK assay. K562 is a standard target for the human NK assay (24) and was used extensively in this study. YAC-l and Fravel, two other continuous lymphoid cell lines, were also used in some experiments. The medium used for continuous culture was RPMI 1640, supplemented with $5 \%$ fetal calf serum. Target cells at $5 \times 10^{6} / 200 \mu \mathrm{l}$ of fetal calf serum were incubated with $0.1 \mathrm{ml} \mathrm{Na}{ }^{51} \mathrm{CrO}_{4}$ (New England Nuclear, Boston, $\mathrm{MA}$, sp act $1.0 \mathrm{mCi} / \mathrm{ml}$ ) for $45 \mathrm{~min}$ at $37^{\circ} \mathrm{C}$. The cells were washed three times with RPMI 1640 containing $\mathrm{AB}$ serum and then placed into the wells of round bottom microtiter plates (Linbro Chemical Company, Hamden, CN). Various numbers of effector cells were added to 5,000 labeled target cells, such that the effector/target (E/ T) ratios were 100:1, 50:1, and 25:1. Final volume in each well was $200 \mu \mathrm{l}$. The plates were incubated for $4 \mathrm{~h}$ at $37^{\circ} \mathrm{C}$ and then centrifuged at $2,000 \mathrm{rpm}$ for $10 \mathrm{~min}$. $100 \mu \mathrm{l}$ of supernatant was removed and placed in borosilicate glass tubes, and counted in an automatic gamma scintillation counter. Spontaneous release was assessed by a series of wells containing no effector cells. Maximum release was obtained by treating a series of wells with Lyzerglobin (J. T. Baker Chemical Co., Bethlehem, PA). The percentage of NK activity was calculated as follows: Percent NK activity $=$ experimental ${ }^{51} \mathrm{Cr}$ release - spontaneous ${ }^{51} \mathrm{Cr}$ release/maximum ${ }^{51} \mathrm{Cr}$ release - spontaneous ${ }^{51} \mathrm{Cr}$ release $\times 100$.

Effector-target conjugates. Effector-target conjugates were quantitated in a manner similar to that described by Roder et al. (6). Briefly, $5 \times 10^{6}$ targets were suspended in RPMI 1640 without serum and $1 \mathrm{mg}$ of fluorescein isothiocyanate (BDH, Chemicals Ltd., Poole, England) dissolved in $1 \mathrm{ml}$ of normal saline was added. The cells were incubated on ice for $15 \mathrm{~min}$, and then washed three times with cold RPMI 1640. $2.5 \times 10^{5}$ fluoresceinated targets were added to $2.5 \times 10^{5}$ glass wool nonadherent PBMC and the mixture was centrifuged at $400 \mathrm{~g}$ for $3 \mathrm{~min}$ and then incubated on ice for $2 \mathrm{~h}$. Effector-target conjugates were identified on a fluorescent microscope. Adventitious associations between cells were eliminated by gently tapping the slide or coverslip. 400 cells were counted in each sample. At a $1: 1 \mathrm{E} / \mathrm{T}$ ratio the percentage of effectors that bound to target cells was counted. At a 50:1 E/T ratio the proportion of targets with adherent effector cells was measured.

Statistical methods. The two-tailed Student's $t$ test was used to determine the significance of differences between the means of two groups. Linear regression analysis was used to compute linear correlation coefficients ( $r$ values) and $P$ values between two variables.

\section{RESULTS}

NK function in SLE. NK activity in SLE patients as a group was significantly decreased relative to normal controls (Fig. 1) at three different $\mathrm{E} / \mathrm{T}$ ratios $(P<0.05)$. Of the 24 SLE patients studied, 17 had significantly decreased NK activity relative to controls. 


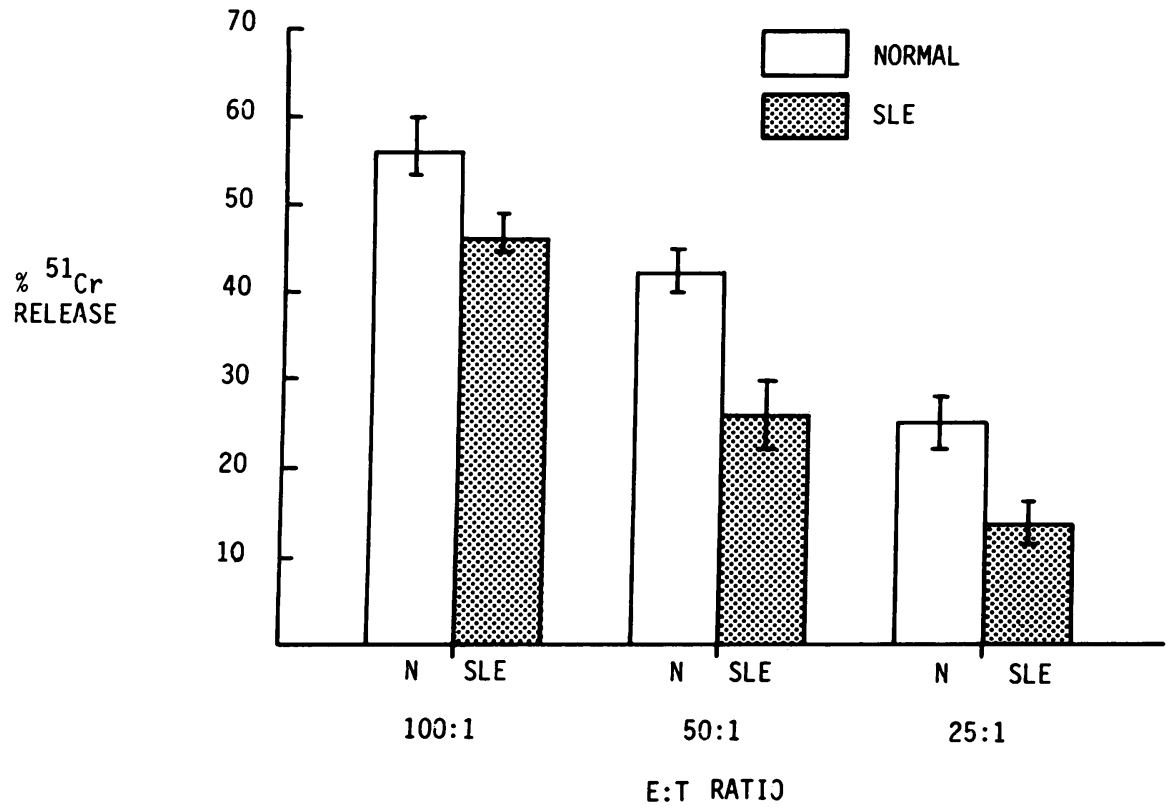

FIGURE 1 NK activity in SLE and normal controls. Bargraph demonstrating decreased NK activity in SLE relative to normal controls at three different $E / T$ ratios (mean $\pm S E$ ). SLE patients $n=24$; controls $n=30$.

NK activity had a significant negative correlation with antinuclear antibody titers, total hemolytic complethe clinical activity score $(r=-0.56, P<0.005)$ (Fig. ment (CH50), or sedimentation rate. Six patients with 2), but was not correlated with corticosteroid dose, decreased NK were followed serially during disease

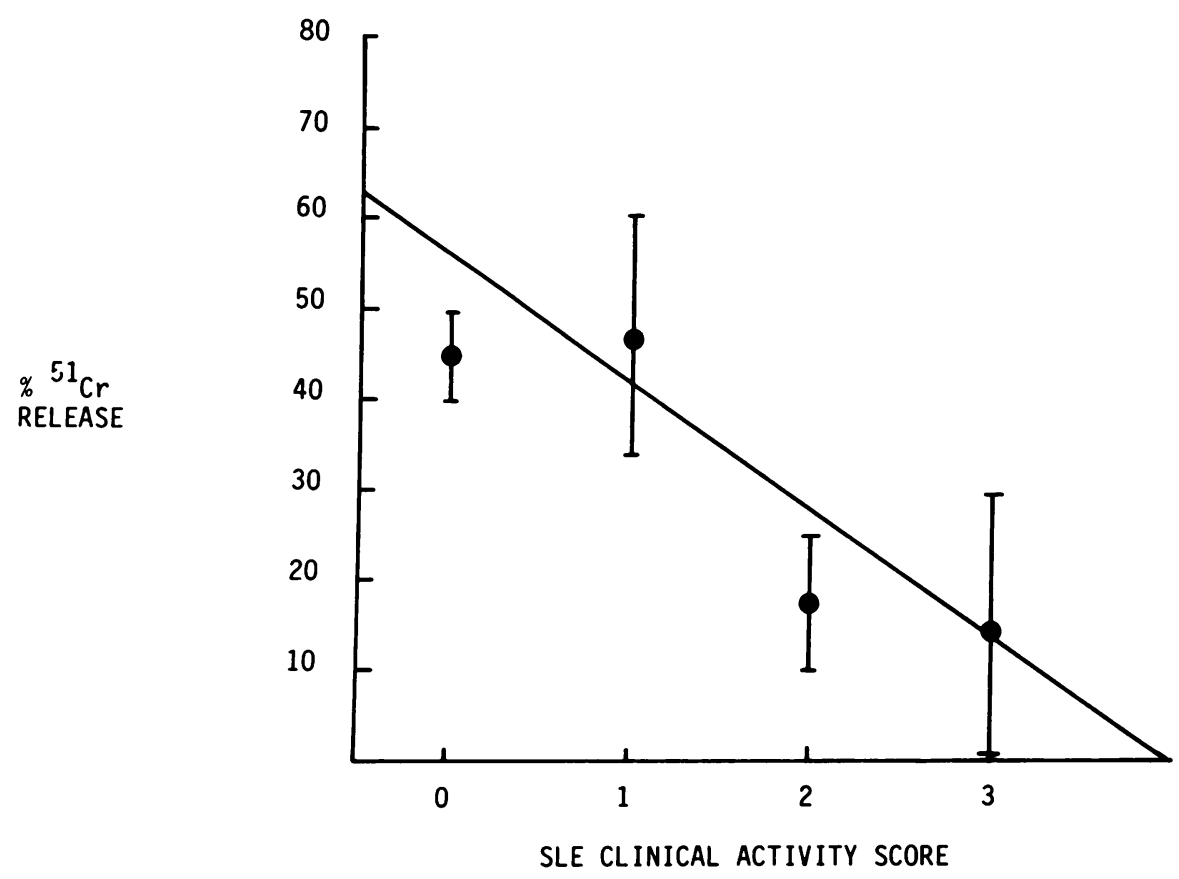

FIGURE 2 SLE NK activity vs. clinical activity score. Graph revealing the significant linear correlation $(r=-0.58, P<0.005)$ between SLE disease activity and NK activity (mean \pm SD). SLE patients $n=24$. 
exacerbations and clinical remissions (Table II). Importantly, patients with decreased NK tended to continue to show decreased NK when studied later, even during remissions. In addition, severely depressed NK activity was associated with clinical exacerbations in SLE disease activity in all six patients. These differences were highly significant $(P<0.05)$. Thus, it appears that SLE disease activity is closely related to deranged NK function.

Effect of 24-h incubation. In an effort to see if soluble factors adherent to the cell membrane might be responsible for decreased NK activity, SLE and normal control PBMC were incubated at $37^{\circ} \mathrm{C}$ for 24 $h$, washed, and then placed into the NK assay. There was no significant change in NK activity at 0 vs. 24 $h$ for either SLE or normal controls (Table III). Similarly, the differences between patients and controls persisted after 24-h incubation.

Depletion of glass adherent cells. SLE patients showed a slightly increased percentage of monocytes in the mononuclear cell suspensions as determined by peroxidase staining, but this difference was not significant $\quad(\mathrm{SLE}=16.8 \pm 6.0 \%, \quad$ normals $=11.8 \pm 5.0 \%$, $P>0.10$ ). There was no clear correlation between NK activity and percentage of monocytes in either patients or controls. Removal of glass wool adherent cells in-

TABLE II

Serial Studies of NK Function in SLE

\begin{tabular}{cccc}
\hline $\begin{array}{c}\text { Patient } \\
\text { identification }\end{array}$ & $\mathrm{NK} \cdot$ activity & $\begin{array}{c}\text { Clinical } \\
\text { activity score }\end{array}$ & Description of exacerbation \\
\hline lat & $24.9 \pm 5.3$ & 1 & Nephritis, rash, arthralgias \\
lb\$ & $15.8 \pm 10$ & 3 & \\
2a & $29.8 \pm 10.4$ & 2 & Serositis, arthritis, vasculitis, \\
2b & $0.0 \pm 10.0$ & 3 & rash \\
3a & $22.5 \pm 19.6$ & 1 & Rash, discoid lupus, \\
3b & $4.2 \pm 3.2$ & 2 & arthralgias \\
4a & $56.1 \pm 9.0$ & 1 & Rash, arthralgias \\
4b & $12.7 \pm 6.5$ & 2 & \\
5a & $17.7 \pm 11.4$ & 1 & Rash, arthralgias \\
5b & $12.4 \pm 3.9$ & 2 & \\
6a & $18.4 \pm 4.4$ & 1 & Rash, arthralgias \\
6b & $5.5 \pm 15.9$ & 2 & \\
Mean \pm SD & & & \\
a & $28.2 \pm 14.4$ & & \\
b & $8.4 \pm 06.0$ & & \\
\hline
\end{tabular}

- Expressed percent chromium release mean \pm SD. Six patients were studied serially during remissions and exacerbations in disease activity.

f a represents clinical remission.

\& b represents clinical exacerbations.
TABLE III

Effect of 24-h Preincubation and Removal of Glass Wool Adherent Cells on NK Activity

\begin{tabular}{|c|c|c|}
\hline & \multicolumn{2}{|c|}{ Effect of 24-h preincubation } \\
\hline & Before & After \\
\hline Normals & $51.9 \pm 16.0^{\circ}$ & $50.0 \pm 10.8(P>0.10)$ \\
\hline \multirow[t]{3}{*}{ SLE } & $27.0 \pm 1.0$ & $24.5 \pm 13.1(P>0.10)$ \\
\hline & \multicolumn{2}{|c|}{ Effect of removal of glass wool adherent cells } \\
\hline & Before & After \\
\hline Normals & $26.2 \pm 13.4 \ddagger$ & $29.3 \pm 17.4(P>0.10)$ \\
\hline SLE & $18.6 \pm 12.3$ & $23.2 \pm 15.2(P>0.10)$ \\
\hline
\end{tabular}

- Mean \pm SD at 50:1, E/T ratio, six patients.

$\downarrow$ Mean \pm SD at $25: 1, \mathrm{E} / \mathrm{T}$ ratio, six patients.

creased NK activity slightly in both controls and SLE patients, but this change was not significant (Table III).

Effect of protease treatment. Because of the possibility of inhibitory proteins binding to effector cells, PBMC from six SLE patients were treated with protease and then incubated for $24 \mathrm{~h}$ before use. SLE PBMC increased slightly in NK activity: before protease $8.52 \pm 6.7 \%$, after protease $17.9 \pm 19.2 \%$, but this difference was not significant $(P>0.10)$. Similarly, PBMC obtained from six matched controls did not change activity when treated with protease: before protease $33.5 \pm 15.6 \%$, after protease $32.2 \pm 9.2 \%$ $(P>0.10)$.

$S L E$ cell culture supernatants. In an effort to determine if SLE cells produced soluble suppressor substances that could inhibit NK activity, 24-h undiluted supernatants from SLE PBMC were incubated with normal control PBMC for $2 \mathrm{~h}$ before the NK assay. At a 25:1 ratio, there was no discernible change in NK activity: normal supernatants $=29.8 \pm 9.8 \%$, SLE supernatants $=28.3 \pm 14.4 \%(P>0.10)$. Thus, unstimulated SLE PBMC do not produce significant NK suppressive factors during a 24-h culture.

Addition of SLE cells to normal PBMC. SLE PBMC were added to normal control PBMC in various ratios as described in the Methods in order to investigate the possibility of suppression by a direct cell-tocell contact. No suppression by such addition was observed.

Indomethacin effect. Indomethacin, a prostaglandin synthetase inhibitor, was added to cultures to discern if prostaglandins might be responsible for the depression of SLE-associated NK activity. Addition of indomethacin caused a significant increase in NK activity after 16-h incubation in both normal controls and SLE patients $(P<0.05)$. This enhancement was 
not noted with a 2 -h preincubation with indomethacin. SLE patients did not increase to normal levels of NK activity. Normal controls and patients responded to indomethacin in a similar fashion, normals increasing by $16.5 \pm 16.7 \%$, and SLE patients increasing by $11.9 \pm 9.5 \%$. The response to indomethacin in both groups was not significantly different $(P<0.10)$.

Addition of poly-I:C and Con A. Poly-I:C and Con $A$ are known inducers of IF production $(25,26)$. These inducers were incubated with PBMC suspensions and cultured for $16 \mathrm{~h}$ before determination of NK activity. As can be seen from Fig. 3 normal controls responded to poly-I:C far better than SLE patients. At a 50:1 ratio the percent increase in lysis was as follows: normal $=20.00 \pm 16 \%$, SLE patients $=4.0 \pm 15.7 \%(P<0.01)$. This effect was similar at different ratios. The effect of Con A on NK was essentially identical to that of poly-I:C. In addition, the difference between the normal and SLE groups became even more significant after addition of IF inducers: normal $=61 \pm 16.3 \%$, SLE patients $=26.3 \pm 22.0 \%(P<0.01)$. Remarkably, six SLE patients with normal base-line NK activity did not respond normally to poly-I:C: base-line SLE $=48.90 \pm 5.5 \%, \mathrm{SLE}+$ poly-I:C $=51.77 \pm 13.6 \%$ with a mean increase of only $2.87 \%$. Thus, SLE patients in general did not appear to respond well to IF inducers, regardless of the unstimulated NK activity.

Effect of IF. To investigate a possible abnormality in response to IF, exogenous $\alpha$-IF was added to PBMC before the addition of targets. Response to IF was highly variable in both normal controls and SLE patients, but as a group normal controls demonstrated a greater increase in IF-induced NK enhancement. Normals increased $12.2 \pm 10.1 \%$ in total lysis vs. SLE that increased only $2.5 \pm 10.0 \%(P<0.05)$ (Fig. 4). Thus, PBMC from SLE patients do not respond well to IF.

Effector-target conjugates. Effector-target conjugates were quantitated to establish if there were abnormalities or an absence of cells capable of binding the K562 targets. First, normal glass wool nonadherent mononuclear cells were tested for lytic capability against cell lines either resistant or susceptible to NK lysis. Simultaneously, the percentage of lymphocytes forming effector-target conjugates was determined. As can be seen from Table IV, only K562, the line susceptible to NK lysis, was readily bound by the mononuclear cells. Thus, binding as has been shown previously (6), is a necessary step in NK lysis, and this particular visual assay was sensitive enough to detect such differences in target-effector binding. Next, the same assay was repeated in six normal controls and six SLE patients (Table V). Although significant differences in NK activity were again evident, there are no significant differences in the number of effector-target conjugates. Thus, the population of glass wool non-

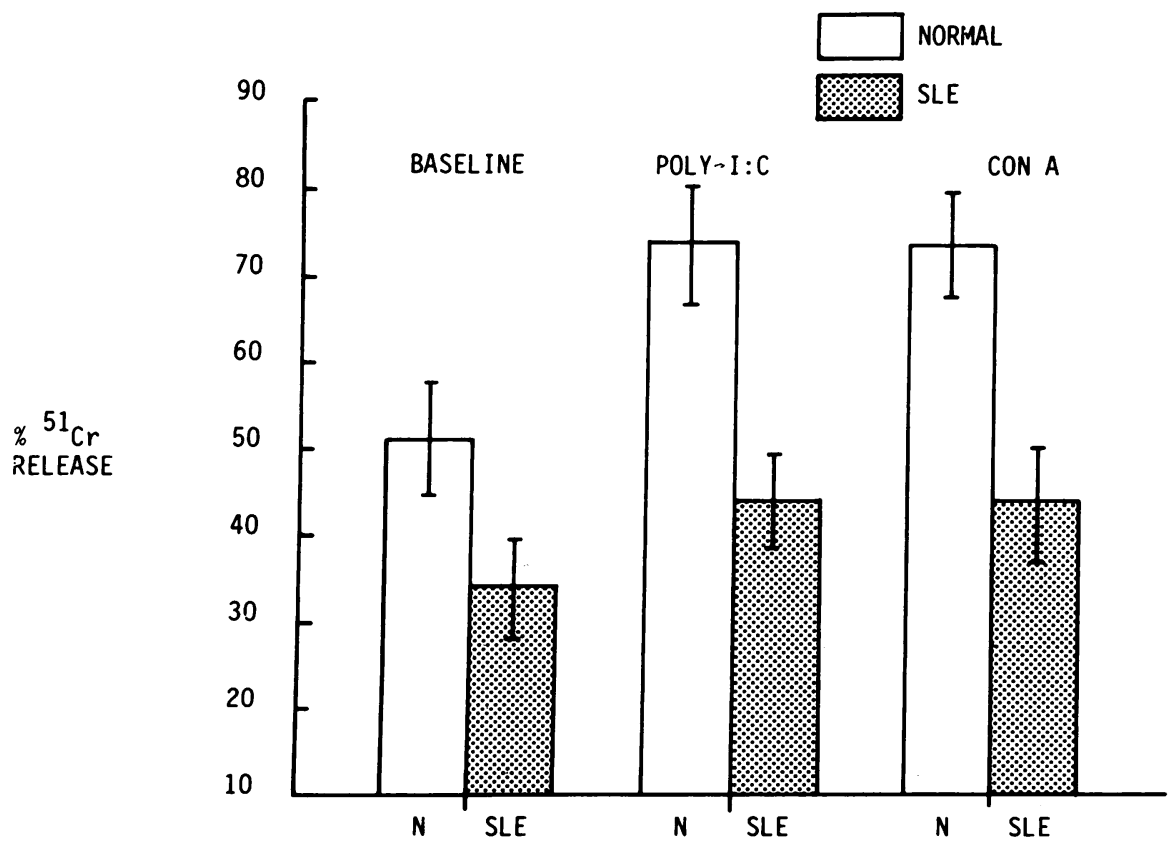

FIGURE 3 Effect of poly-I:C and Con A on NK cells in normal controls and SLE patients. Bargraph showing effect of poly-I:C and Con A on NK activity in normal controls $(n=30)$ and SLE $(n=23)$ lymphocytes at a 50:1 E/T ratio (mean \pm SE). 


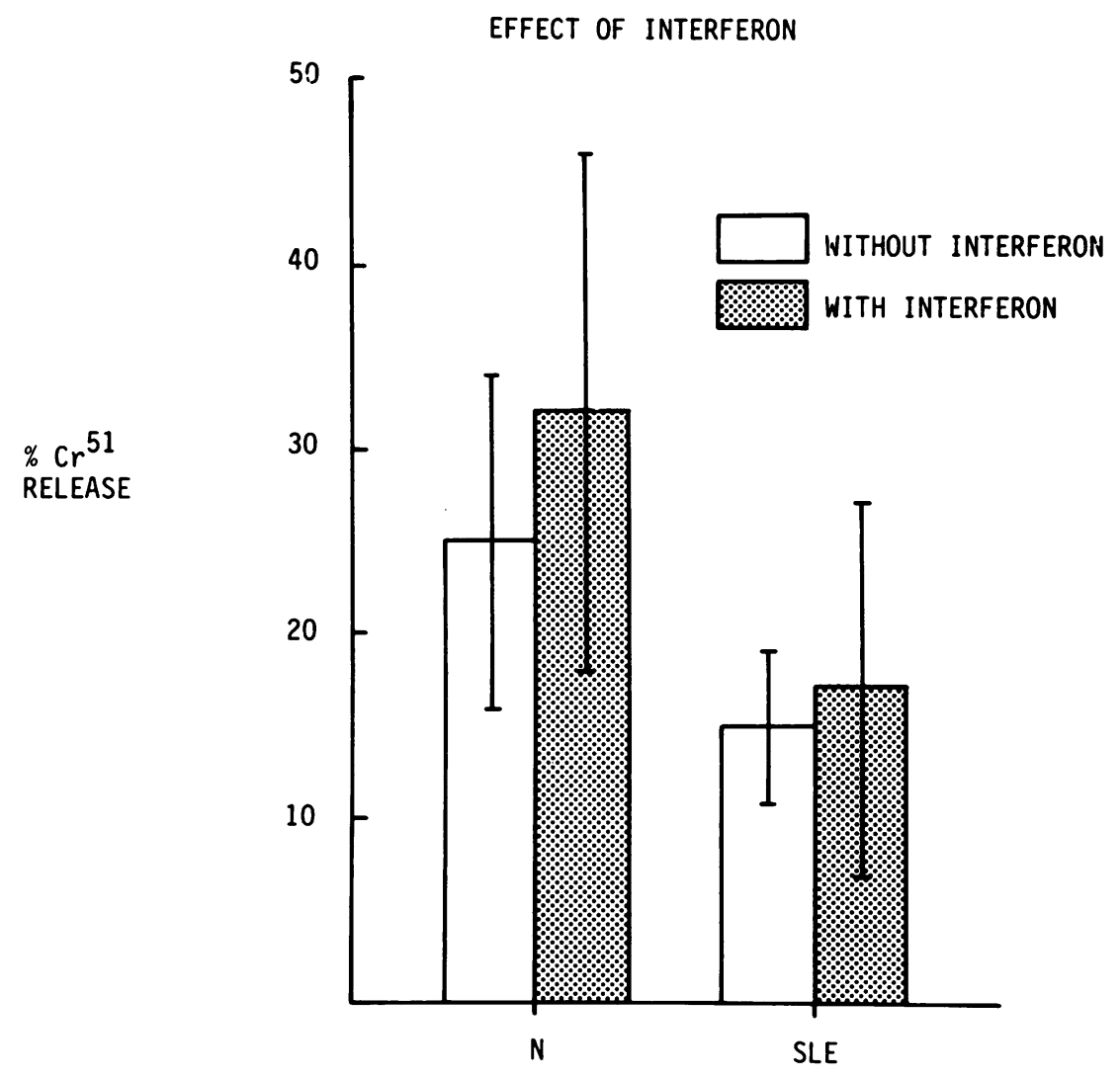

Figure 4 Effect of IF. Bargraph demonstrating impaired response to exogenous IF in SLE $(n=23)$ at a $25: 1 \mathrm{E} / \mathrm{T}$ ratio (mean $\pm \mathrm{SD})$.

adherent cells capable of binding the K562 target and hence possessing the potential of lysing this target were not significantly decreased in SLE.

NKCF release. NKCF release as measured by the percent lysis of $\mathrm{K} 562$ cells by Con A supernatants was $19.1 \pm 4.1 \%$ in SLE patients $(n=8)$ and $36.3 \pm 6.5 \%$ in normal controls $(n=6)$. This difference is significant $(P<0.05)$. Interestingly, three SLE patients with nor-

TABLE IV

NK Activity and Number of Effector-Target Conjugates with Different Targets

\begin{tabular}{cccc}
\hline \multicolumn{1}{c}{ Cell line } & K562 & YAC-1 & Fravel \\
\hline Percent ${ }^{51} \mathrm{Cr}$ release & $46.2 \pm 6.32^{\circ}$ & $\begin{array}{c}15.6 \pm 19.6 \\
(P<0.02)\end{array}$ & $\begin{array}{c}4.68 \pm 8.8 \\
(P<0.02)\end{array}$ \\
$\begin{array}{l}\text { Effector-target } \\
\text { conjugates }\end{array}$ & $13.1 \pm 2.0 \ddagger$ & $\begin{array}{c}4.6 \pm 3.6 \\
(P<0.02)\end{array}$ & $\begin{array}{c}5.2 \pm 3.2 \\
(P<0.02)\end{array}$ \\
\hline
\end{tabular}

- Mean $\pm S D, E / T$ ratio 25:1. Each experiment was performed in quadruplicate with four different normals.

$\$$ Mean $\pm \mathrm{SD}, \mathrm{E} / \mathrm{T}$ ratio $1: 1$. Each experiment was performed in quadruplicate with four different normals. mal base-line NK activity, but an impaired response to IF and IF inducers had an average NKCF release of $25.0 \pm 4.0 \%$. This is below that noted for normals and yet above that found for SLE patients with impaired base-line NK cell function.

\section{DISCUSSION}

This study confirms that NK activity in SLE patients as a group was markedly decreased relative to normal

TABLE V

Effector-Target Binding in SLE

\begin{tabular}{lccc}
\hline & & \multicolumn{2}{c}{ Percent effector-target conjugates } \\
\cline { 3 - 4 } & Percent lysis & $50: 1^{\bullet}$ & $1: 1^{\bullet}$ \\
\hline $\begin{array}{l}\text { Normal control } \\
n=6\end{array}$ & & & \\
SLE & $45.3 \pm 11.5 \ddagger$ & $20.6 \pm 10.9$ & $11.5 \pm 2.5$ \\
$n=6$ & & & \\
$P \quad$ & $25.0 \pm 14.8 \ddagger$ & $16.1 \pm 10.1$ & $9.8 \pm 2.9$ \\
& $<0.05$ & $>0.20$ & $>0.20$ \\
\hline
\end{tabular}

- $\mathrm{E} / \mathrm{T}$ ratios used for this visual assay (Methods). \$ Mean \pm SD, E/T ratio 50:1 (K562). 
controls $(13,14)$. No correlations were found between commonly measured laboratory parameters; however, the clinical activity score was significantly correlated with decreases in NK activity. Moreover, certain patients with markedly decreased NK activity tended to have abnormal NK function even during disease remissions. Exacerbations in these patients were associated with a definite decrease in NK function. No relationship was found between corticosteroid dose and NK activity. These findings are in agreement with those of Hoffman (8) and Karsh et al. (13). Disease exacerbations in SLE are associated with increased circulating immune complexes and ALA, both of which have been implicated as a cause of depressed NK activity in $\operatorname{SLE}(13,14)$. It is no surprise, then, that disease exacerbations should be associated with a decrease in NK function.

A decrease in NK activity in SLE could be the result of several factors, including the presence of suppressor cells, increased numbers of monocytes, inactivation of effector cells, inhibition of effector-target binding, or actual depletion of the NK effector population. Results presented here provide no evidence for the importance or presence of suppressor cells as a cause of the defect in NK activity in SLE. The sequential addition of SLE cells to normal cells, the 24-h preincubation of SLE cells, or the addition of 24-h supernatants from SLE cells to normal cells demonstrated nothing that could confirm the presence of a cell-mediated suppressive mechanism.

In certain disease states monocytes can be selectively enriched by Ficoll-Hypaque separation and can interfere with in vitro assays of lymphocyte function (27). Indeed, the percentage of monocytes in SLE was greater than normal controls. However, removal of monocytes by glass-wool adherence did not result in an increase in NK activity for either SLE patients or controls. Monocytes can also secrete prostaglandins (28), and certain prostaglandins are highly suppressive of NK activity $(29,30)$. Indomethacin caused a significant increase in NK activity in both patients and controls, presumably from inhibition of base-line production of prostaglandins. This increase did not correct the SLE NK abnormality relative to normals, implying that the basic defect is not due to increased prostaglandin synthesis in SLE with subsequent NK suppression.

In this study, effector-target conjugates were quantitated and there was no statistical difference between SLE patients and normal controls, despite concomitant differences in NK activity. Thus, SLE lymphocytes seem to bind to tumor targets as frequently as normal lymphocytes. These findings imply inactivation or dysfunction of at least a portion of the NK effector cells. The presence of serum lymphoreactive antibodies and immune complexes could certainly account for some of the observed dysfunction of the NK cell in SLE. Winchester et al. (31) reported that overnight culture of SLE lymphocytes was an efficient procedure for the removal of adsorbed autoantibody. Merrill et al. (32) also reported that the NK suppressive effects of immune complexes can be reversed by overnight culture. In our study, however, overnight incubation of SLE cells or treatment with protease did not influence NK activity significantly. This suggests that although ALA and immune complexes may be important in the pathogenesis of some observed decreases in NK activity in SLE, other inhibitory mechanisms must also be present and are not easily reversible.

NK activity in SLE could be decreased due to reduction or deletion of circulating NK effector cells. The NK cell is reported to have Fc receptors, and, indeed, there are reports of decreased numbers of Fc receptor-bearing cells in SLE (33). In addition, the frequency of $\mathrm{L}$ cells (which possess NK activity), is also reported to be decreased in SLE (34). Deletion of effector cells is certainly consistent with the data of Goto et al. (14) who reported lymphocytotoxic antibodies reactive against NK effectors. Our study, however, despite considerable differences in NK activity shows no significant differences in cells binding the K562 target. Recent studies in our laboratory with the monoclonal antibody HNK-1 has confirmed that the population of cells responsible for NK are not decreased in SLE (35). This implies that there is at least no gross deletion of effector cells in SLE.

SLE lymphocytes did not respond normally to exogenous IF. This lack of NK enhancement by IF in SLE patients was also seen in some patients with normal resting NK function, as well as those with decreased NK activity. These results are consistent with those of Fitzharris et al. (36). IF is thought to enhance NK activity by increasing recycling and also by recruitment of pre-NK cells $(37,38)$. Thus, after exposure to IF, pre-NK cells are converted into active NK cells and existing NK cells become more active. The poor response to IF noted in some patients with normal base-line NK implies that either the IF response mechanisms are blocked in some manner or that other overriding inhibitory processes are involved.

Serum IF levels have been reported to be elevated in SLE (39). Because of elevated endogenous levels of IF, the NK enhancement may have already occurred in SLE lymphocytes and thus additional exogenous IF would have little effect in further enhancing already elevated lytic activity. However, our findings are not consistent with this possibility. First, SLE sera tends to suppress, not enhance, NK activity. Second, the effect of IF is transitory if washed from the effector cell (37). In our study after 24 -h incubation no decrease 
in NK activity was noted in SLE lymphocytes. This implies that IF-mediated enhancement had not been present. Third, the supernatants from SLE lymphocytes cultured overnight did not enhance normal NK activity implying that base-line IF production in SLE lymphocytes is quite low. Finally, the concentrations of IF used in these experiments were $200 \mathrm{U} / \mathrm{ml}$, which were higher than those in SLE sera reported by Hooks et al. (39). Thus, the lack of response to IF in SLE appears to be a primary abnormality and not an artifact produced by previous IF priming.

The IF inducers poly-I:C and Con A did not enhance NK activity normally in SLE. This in itself is not surprising since SLE cells do not respond to IF in a normal manner. However, recently Neighbour et al. (40) have reported decreased IF production in SLE leukocytes when stimulated with IF inducers. We have confirmed this recently in our laboratory. This abnormality certainly compounds the perceived complexity of NK modulation in SLE. It implicates abnormalities in both NK effectors as well as other cells that produce IF.

Wright and Bonavida $(17,23)$ have recently described the existence of soluble cytotoxic factors released by NK cells that mediate lysis of NK cell sensitive tumor targets. These cytotoxic factors (NKCF) can be released into the supernatant on exposure to various mitogens (23). Presumably to effect lysis, an NK cell must first bind to a sensitive tumor target and then release NKCF that acts on the cell membrane of the target and results in lysis. Our study has demonstrated that there is no depletion of target binding cells in SLE, rather, there is a marked decrease in NKCF release. This demonstrates for the first time that impaired NK function noted in SLE may be secondary to a defect on the cellular level that results in impaired release of a soluble cytotoxic factor.

\section{ACKNOWLEDGMENTS}

We sincerely thank Ms. Sandra McCollum and Ms. Lori Bennett for their advice and expert technical assistance in the preparation of this manuscript.

This work was supported by National Institutes of Health grants R01 CA-24873-04 and 2 T32 AM 07173-07.

\section{REFERENCES}

1. Marx, J. 1980. Natural killer cells help defend the body. Science (Wash. DC). 7: 624-626.

2. Heberman, R. B., and H. T. Holden. 1979. Natural killer cells as antitumor effector cells. J. Natl. Cancer Inst. 62: 441-444.

3. Fujimiya, Y., L. A. Babiuk, and B. T. Rouse. 1978. Direct lymphocytotoxicity against herpes simplex virus-infected cells. Can. J. Microbiol. 24: 1076-1081.

4. Timonen, T., J. R. Ortaldo, and R. B. Herberman. 1981. Characteristics of human large granular lymphocytes and relationship to natural killer and $\mathrm{K}$ cells. J. Exp. Med. 153: 564-582.
5. Timonen, T., E. Saksela, A. Runki, and P. Huyry. 1979. Fractionation, morphological and functional characterization of effector cells responsible for human natural killer activity against cell-line targets. Cell. Immunol. 98: 133-148.

6. Roder J. C., S. Argov, M. Klein, C. Peterson, R. Kiessling, $K$. Anderson, and M. Hansson. 1980. Target-effector interaction in the natural killer system: $V$. Energy requirements, membrane integrity, and the possible involvement of lysosomal enzymes. Immunology. 40: 107-116.

7. Targan, S., E. Grim, and B. Bonavida. 1980. A singlecell marker of active NK cytotoxicity: only a fraction of target binding lymphocytes are killer cells. J. Clin. Lab. Immunol. 4: 165-168.

8. Hoffman, T. 1980. Natural killer function in systemic lupus erythematosus. Arthritis Rheum. 23: 30-35.

9. Goto, M., K. Tanimoto, T. Chihura, and Y. Horiuchi. 1981. Natural cell-mediated cytotoxicity in Sjögren's syndrome and rheumatoid arthritis. Arthritis Rheum. 24: $1377-1382$

10. Roder, J. C., Haliotist, M. Klein, S. Lorec, J. Jeh, J. Ortaldo, R. B. Herberman, P. Katz, and A. S. Fauci. 1980. A new immunodeficiency disorder in humans involving NK cells. Nature (Lond.). 284: 553-555.

11. Hersey, P., A. Edwards, and W. H. McCarthy. 1980 Tumor-related changes in natural killer activity in melanoma patients. Influence of stage of disease, tumor thickness, and age of patients. Int. J. Cancer. 25: 187194.

12. Kadish, A. S., A. T. Doule, E. H. Steinhauer, and N. A. Ghossein. 1981. Natural cytotoxicity and interferon production in human cancer; deficient natural killer activity and normal interferon production in patients with advanced disease. J. Immunol. 127: 1817-1822.

13. Karsh, J., G. Dorval, and C. K. Osterland. 1981. Natural cytotoxicity in rheumatoid arthritis and systemic lupus erythematosus. Clin. Immunol. Immunopathol. 19: 437446.

14. Goto, M., K. Tanimoto, and Y. Horiuchi. 1980. Natural cell-mediated cytotoxicity in systemic lupus erythematosus. Arthritis Rheum. 23: 1274-1281.

15. Decker, J. L., A. D. Steinberg, J. L. Reinersten, P. H. Plotz, J. E. Balow, and J. H. Klippel. 1979. NIH Conference. Systemic lupus erythematosus: Evolving concepts. Ann. Int. Med. 91: 587-564.

16. Fauci, A. S., and H. M. Moutsopoulos. 1981. Polyclonally triggered $\mathrm{B}$ cells in the peripheral blood and bone marrow of normal individuals and in patients with systemic lupus erythematosus and primary Sjögren's syndrome. Arthritis Rheum. 24: 577-584.

17. Wright, S. C., and B. Bonavida. 1982. Studies on the mechanism of natural killer (NK) cell-mediated cytotoxicity (CMC). J. Immunol. 129: 433-439.

18. Cohen, A. S., W. E. Reynolds, E. C. Franklin, M. W. Kulda, L. E. Shulman, and S. E. Wallace. 1971. Preliminary criteria for the classification of systemic lupus erythematosus. Bull. Rheum. Dis. 21: 643-648.

19. Barada, F. A., B. S. Andrews, J. S. Davis, and R. D. Taylor. 1981. Antibodies to SM in patients with systemic lupus erythematosus. Arthritis Rheum. 24: 1236-1245.

20. Boyum, A. J. 1968. Isolation of mononuclear cells and granulocytes from human blood. Scand. J. Clin. Lab. Invest. 21 (Suppl. 97): 77-89.

21. Yam, L. T., C. Y. Li, and W. H. Crosby. 1971. Cytochemical identification of monocytes and granulocytes. Am. J. Pathol. 55: 283-290.

22. Lobo, P. I., J. B. Winfield, A. Cragi, and F. B. Westervel. 
1977. Utility of protease-digested human peripheral blood lymphocytes for the detection of lymphocyte-reactive alloantibodies by indirect immunofluorescence. Transplantation (Baltimore). 23: 16-21.

23. Wright, S. C., and B. Bonavida. 1981. Selective lysis of NK-sensitive target cells by a soluble mediator released from murine spleen cells and human peripheral blood lymphocytes. J. Immunol. 1260: 1516-1524.

24. Klein, E., H. Ben-Bassat, and H. Newmann. 1976. Properties of the K562 cell line, derived from a patient with chronic myeloid leukemia. Int. J. Cancer. 18: 421-431.

25. Zarling, J. M., J. Schlais, L. Eskra, J. J. Greene, P. O. P. Tso, and W. A. Carter. 1980. Augmentation of human natural killer cell activity by polyinosinic acid-polycytidylic acid and its nontoxic mismatched analogues. $J$. Immunol. 124: 1852-1857.

26. Neighbour, P. A., and A. I. Grayzel. 1981. Interferon production in vitro by leukocytes from patients with systemic lupus erythematosus and rheumatoid arthritis. Clin. Exp. Immunol. 45: 576-582.

27. Holm, G., M. Bjorkholm, B. Johansson, H. Mellstedt, and C. Lindemalm. 1982. Monocyte function in Hodgkin's disease. Clin. Exp. Immunol. 47: 162-168.

28. Goodwin, J. S., R. P. Messner, A. D. Bankhurst, G. T. Peake, J. H. Saiki, and R. C. Williams, Jr. 1977. Prostaglandin-producing suppressor cells in Hodgkin's disease. N. Engl. J. Med. 297: 297-301.

29. Roder, J. C., and M. Klein. 1979. Target-effector interaction in the natural killer cell system: IV. Modulation by cyclic nucleotides. J. Immunol. 123: 2785-2790.

30. Bankhurst, A. D. 1982 . The modulation of human natural cytotoxicity by prostaglandins. J. Lab. Clin. Immunol. 7: 85-91.

31. Winchester, R. J., J. B. Winfield, F. Siegal, P. Wernet, Z. Bentwich, and H. G. Kunkel. 1974. Analyses of lymphocytes from patients with rheumatoid arthritis and systemic lupus erythematosus. Occurrence of interfering cold-reactive antilymphocyte antibodies. J. Clin. Invest. 54: 1082-1092.

32. Merrill, J. E., M. Ullberg, and M. Jonda. 1981. Influence of IgG and IgM receptor triggering on human natural killer cytotoxicity measured on the level of the single effector cell. Eur. J. Immunol. 11: 536-541.

33. Hamilton, M. E., and J. B. Winfield. 1979. T $\gamma$ cells in systemic lupus erythematosus: variation with disease activity. Arthritis Rheum. 22: 1-6.

34. Horwitz, D. A., and K. Juul-Nielsen. 1977. Human blood L-lymphocytes in patients with active systemic lupus erythematosus, rheumatoid arthritis, and scleroderma: a comparison with $\mathrm{T}$ and $\mathrm{B}$ cells. Clin. Exp. Immunol. 30: $370-378$.

35. Abo, T., and C. M. Balch. 1981. A differentiation antigen of human NK and $\mathrm{K}$ cells identified by a monoclonal antibody (HNK-1). J. Immunol. 127: 1024-1029.

36. Fitzharris, P., J. Alcorer, H. A. F. Stephens. R. A. Knight, and M. L. Snaith. 1982. Insensitivity to interferon of NK cells from patients with systemic lupus erythematosus. Clin. Exp. Immunol. 47: 110-118.

37. Silva, A., B. Banavida, and S. Targan. 1980. Mode of action of interferon-mediated modulation of natural killer cytotoxic activity: recruitment of pre-NK cells and enhanced kinetics of lysis. J. Immunol. 125: 474-484.

38. Ullberg, M., J. Merril, and M. Jondal. 1981. Interferoninduced NK augmentation in humans: an analysis of target recognition, effector cell recruitment, and effector cell recycling. Scand. J. Immunol. 14: 285-292.

39. Hooks, J. J., H. M. Moutsopoulos, G. Geiss, N. I. Stuhl, J. L. Decker, and Notkins. 1979. Immune interferon in the circulation and patients with autoimmune disease. N. Engl. J. Med. 301: 5-8.

40. Neighbor, P. A., and A. I. Grayzel. 1981. Interferon production in vitro by leukocytes from patients with systemic lupus erythematosus and rheumatoid arthritis. Clin. Exp. Immunol. 45: 576-582. 